\section{Tuber Initiation in Hydroponically Grown Potatoes by Alteration of Solution pH}

\author{
Waylen Y. Wan, Weixing Cao, and Theodore W. Tibbitts \\ Department of Horticulture, University of Wisconsin-Madison, Madison, \\ WI 53706
}

\begin{abstract}
Additional index words. Solarium tuberosum, tuberization, solution culture
Abstract. Because tuberization in potatoes (Solarium tuberosum L.) reportedly is inhibited when stolons are immersed in liquid, this study was conducted to determine the effect of intermittent $\mathrm{pH}$ reductions of the nutrient solution on tuber induction of potatoes in solution culture. Tissue-culture potato plantlets were transplanted into solutions maintained at $\mathrm{pH}$ 5.5. The $\mathrm{pH}$ of the nutrient solution was changed to 3.5 and 4.0 for 10 hours on each of three dates $(30,35$, and 40 days after transplanting). For the $\mathbf{p H} 3.5$ treatment, tubers were observed first on day 42 and averaged 140 tubers per plant at harvest on day 54. For the pH 4.0 treatment, tubers were observed first on day 48 and averaged 40 tubers per plant at harvest. At a constant pH 5.5, tubers were observed on day 52 and averaged two tubers per plant at harvest. Plants with the intermittent pH 3.5 had smaller shoots and roots with shorter and thicker stolons compared to constant $\mathrm{pH}$ 5.5. With the intermittent pH 4.0, plants were of similar size, but stolons were shorter and slightly thickener compared to those from $\mathrm{pH}$ 5.5. Mineral composition of leaf tissues at harvest was similar for the three $\mathrm{pH}$ treatments. These results indicate that regulation of solution $\mathrm{pH}$ can be a useful technique for inducing tuberization in potatoes.
\end{abstract}

Tuber initiation in potatoes occurs readily in solid matrix culture (Tibbitts and Cao, 1994; Tibbitts and Wheeler, 1987) and efficiently with nutrient film techniques (Wheeler et al., 1990). Although tuberization is inhibited when roots and stolons are immersed in solution or subjected to continuous mist culture (Tibbitts and Cao, 1994), tuberization under these hydroponic procedures can be promoted under certain stress conditions. In solution culture, $\mathrm{N}$ deficiency promoted tuberization (Krauss and Marschner, 1982). In mist culture, $\mathrm{N}$ deficiency and interruption of mist for $12 \mathrm{~h}$ induced rapid tuberization (unpublished data). Tubenzation does occur in solution culture when the container becomes filled with roots and stolons. Vreugdenhil and Struik (1989) suggested that the lack of mechanical resistance on the stolons prevents tuberization, yet efforts to place restriction on stolons have not promoted tuberization. This poor tuberization in solution culture limits the value of solution culture techniques for growing potatoes in controlled-environment facilities.

In a solution culture experiment, a low $\mathrm{pH}$ was induced accidentally for several hours in the solution, and small tubers were observed on the plants a few days later (unpublished data). This incident suggested that tuber initiation on plants grown in solution culture might

Received for publication 12 July 1993. Accepted for publication 17 Nov. 1993. Supported by the College of Agricultural and Life Sciences, Univ. of Wisconsin-Madison, and National Aeronautics and Space Administration grant NCC-2-301. The cost of publishing this paper was defrayed in part by the payment of page charges. Under postal regulations, this paper therefore must be hereby marked advertisement solely to indicate this fact. be induced by short-term reductions in solution $\mathrm{pH}$.

Potato plants adapt well to acidic conditions (MacLean et al., 1967; Smith, 1938), with optimum growth obtained between $\mathrm{pH} 5$ and 6 (Cao and Tibbitts, 1994; McLean and Brown, 1984). Potatoes grown at low soil $\mathrm{pH}$ matured earlier and had a higher tuber : top ratio than those grown at normal $\mathrm{pH}$ (Smith, 1938). The ambient $\mathrm{pH}$ has been reported to significantly affect nutrient uptake and growth of many crop plants, particularly in solution cultures (Islam et al., 1980; Jariel et al., 1991). At very acidic $\mathrm{pH}$, growth can be depressed through $\mathrm{pH}$-induced indirect effects of toxicity or deficiency of certain elements or from direct root injury by excess hydrogen.

Our objective was to establish if intermittent $\mathrm{pH}$ reductions in solution culture could induce tuber formation in potatoes without producing significant injury to the plants.

\section{Materials and Methods}

The experiment was conducted in a walk-in growth chamber at the Univ. of WisconsinMadison. A recirculating solution culture system was used to grow 'Norland' potato plants (Fig. 1). The culture containers were clear acrylic. They were $25 \mathrm{~cm}$ long on each side with a 15-liter capacity. Container surfaces were covered with an opaque polyethylene plastic sheeting with a white outer surface and black inner surface to exclude light and minimize solution heating. A plastic screen was placed halfway into the solution to confine stolons and tubers within the top of the container. Around opening was made in the cover, of the container and a foam plug was inserted to support plants.

The nutrient solution was a modified half-strength Hoagland solution (Hammer et al.,1978) providing only nitrate N. The solution was supplied continuously to each container at $120 \pm 10 \mathrm{ml} \cdot \mathrm{min}^{-1}$ through a tube at the center of the bottom of each container and drained out from a tube at the top of the container that maintained the solution level $1.5 \mathrm{~cm}$ below the cover. The solution was aerated with an air diffuser at the bottom of the container. The solution was recirculated through a 19-liter opaque-plastic jar. The solution in the jar was maintained at a constant

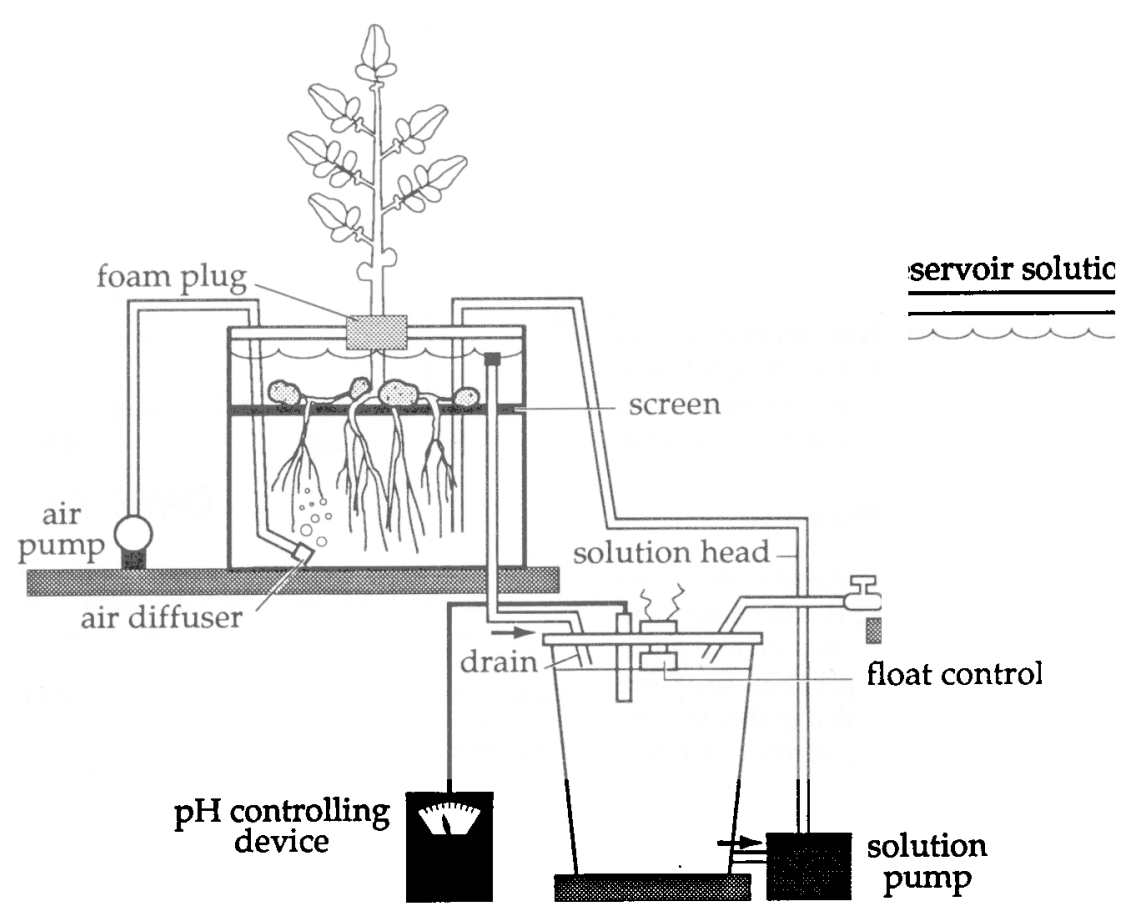

Fig. 1. Diagram of solution culture apparatus used in this experiment. 
level with an automatic float switch that controlled gravity flow from a 200-liter reservoir tank. Solution $\mathrm{pH}$ was maintained at 5.5 with an automatic $\mathrm{pH}$ controller using $0.5 \mathrm{NH}_{2} \mathrm{SO}_{4}$. Conductivity of the solution was monitored every 3 or 6 days and adjusted when it varied more than $10 \%$ from the supply solution by releasing part of the solution in the plastic jar and adding concentrated stock solutions or distilled water, as required.

Plants were raised from micropropagated stem cuttings grown in sterile agar culture (Tibbitts and Wheeler, 1987). A uniform single plantlet, 21 days old, was transplanted into each culture container. Transplants were covered for 3 days with clear plastic cups to minimize transplant shock.

During the experiment, light period was 12 $\mathrm{h}$ provided with cool-white fluorescent lamps, and photosynthetic photon flux was $390 \pm 20$ $\mu \mathrm{mol} \cdot \mathrm{m}^{-2} \cdot \mathrm{s}^{-1}$ at the top of the canopy. Temperature was $18 \pm 0.3 \mathrm{C}$ during the light and 15 $\pm 0.6 \mathrm{C}$ during the dark periods. Relative humidity was constant at $75 \% \pm 3 \%$ daily. The $\mathrm{CO}_{2}$ level was ambient at $\approx 350 \mu 1 \cdot$ liter $^{-1}$.

Three times after transplanting (day 30,35, and 40), the solution recirculation was turned off for $10 \mathrm{~h}$ and the $\mathrm{pH}$ treatments $(3.5,4.0$, and constant 5.5) were established for that period. For the $\mathrm{pH} 3.5$ and 4.0 treatments, the $\mathrm{pH}$ was lowered with an addition of $0.5 \mathrm{NH}_{2} \mathrm{SO}_{4}$ and raised at the end of each 10-h period with 0.5 $\mathbf{N} \mathrm{KOH}$. The $\mathrm{pH}$ was adjusted to the appropriate level every hour during each of the 10-h periods. The design was a randomized complete block with three replications. Following the $\mathrm{pH}$ treatment at 30 days, tuber initiation and stolon morphology were examined visually, and tubers were counted every other day. Any enlargement of a stolon tip equivalent to twice the diameter of the stolon was recorded as a tuber.

Plants were harvested 54 days after being transplanted and separated into leaves, stems, tubers, and roots plus stolons. Plant material was oven-dried at $70 \mathrm{C}$ for 2 days for dry weight determinations. We sampled fully expanded green leaflets for mineral concentrations and analyzed them with inductively coupled plasma-emission spectrophotometry. Tissue $\mathrm{N}$ concentration was determined with the micro-Kjeldahl method (Jones et al., 1991). We performed an analysis of variance on tuber number and dry weight data. When $\mathrm{F}$ was significant at $P<0.05$, treatment means were separated with Duncan's multiple range test.

\section{Results and Discussion}

Tuber initiation was induced in the plants subjected to intermittent $\mathrm{pH}$ reductions compared to constant $\mathrm{pH} 5.5$; the induction was greatest with the lowest $\mathrm{pH}$ (Fig. 2). Tuber initiation started on the 10th day after the first $\mathrm{pH} 3.5$ treatment, and the number of tubers increased significantly over the remaining 14 days. At harvest, 24 days after the first $\mathrm{pH}$ lowering, there were 140 tubers per plant. For the $\mathrm{pH} 4.0$ treatment, tuber initiation was delayed 6 days compared to $\mathrm{pH} 3.5$. The tuber initiation was later, and final tuber count (40 per plant) was significantly lower than with $\mathrm{pH} 3.5$. For the constant $\mathrm{pH}$ 5.5, tuber initiation was not apparent until 2 days before harvest, and there were never more than two per plant. These results demonstrate that $\mathrm{pH}$ reductions at certain growth stages can induce tuber initiation in potatoes grown in solution culture.

The experimental variation in the time of induction and number of tubers was much greater with $\mathrm{pH} 4.0$ than with $\mathrm{pH} 3.5$ (Fig. 2). The data imply that $\mathrm{pH} 4.0$ is close to a critical low $\mathrm{pH}$ for effective tuber induction in potatoes. In the previous accidental $\mathrm{pH}$ reduction (below $\mathrm{pH} 4.0$ ), tuber initiation was seen at 4 days after $\mathrm{pH}$ reduction, compared to 10 days in this study. The plants in that study were at a more mature stage $(\approx 40$ days after transplanting) than in this study (30 days after transplanting). Thus, we suspect that in our study the first $\mathrm{pH}$ change was imposed before the plants were in an inductive state that would permit tuber initiation on stolons. However, it should be recognized that plant maturation rate, and thus effective time for acid treatment, would vary with environmental conditions.

Growth of shoots, roots, and stolons was affected by the intermittent $\mathrm{pH}$ reductions. Shoot and root dry weights were lower and

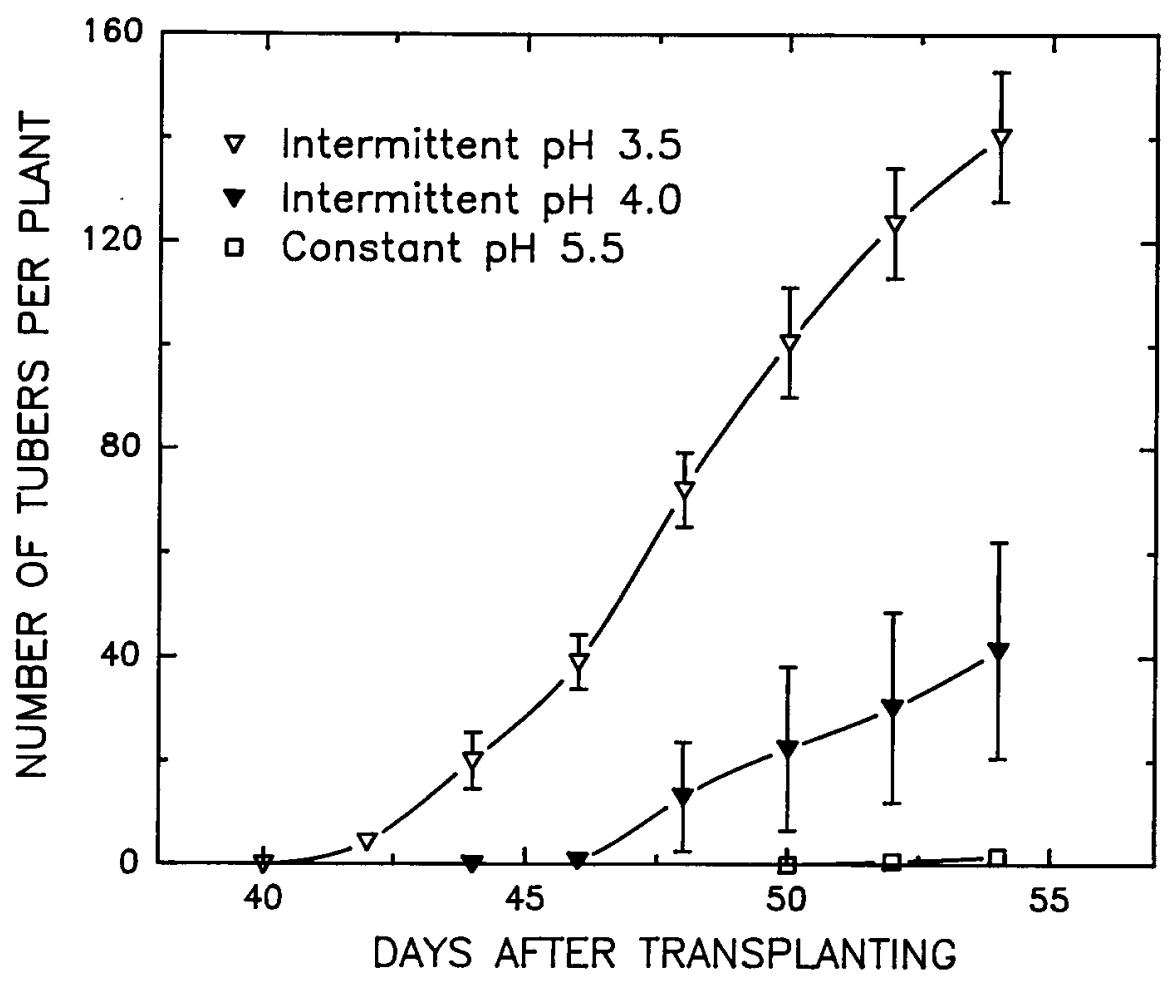

Fig. 2. Time course response of tuber initiation to three $\mathrm{pH}$ treatments. For the intermittent $\mathrm{pH}$, plants were subjected to $\mathrm{pH} 3.5$ or 4.0 for $10 \mathrm{~h}$ on each of three dates $(30,35$, and 40 days after transplanting). Vertical bars represent SE of treatment means at the times noted.

Table 1. Dry weights of various parts of potato plants grown for 54 days with one of three $\mathrm{pH}$ treatments.

\begin{tabular}{lccccc}
\hline \hline Treatment & Shoots & Stolons & Roots & Tubers & Total \\
\cline { 2 - 6 }$(\mathrm{pH})$ & \multicolumn{5}{c}{ g/plant } \\
Intermittent 3.5 & $26.7 \mathrm{~b}^{\mathrm{y}}$ & $4.9 \mathrm{a}$ & $3.5 \mathrm{~b}$ & $6.6 \mathrm{a}$ & $41.7 \mathrm{~b}$ \\
Intermittent 4.0 & $54.9 \mathrm{a}$ & $5.7 \mathrm{a}$ & $5.2 \mathrm{a}$ & $1.0 \mathrm{~b}$ & $66.8 \mathrm{a}$ \\
Constant 5.5 & $48.5 \mathrm{a}$ & $4.2 \mathrm{a}$ & $5.0 \mathrm{a}$ & $<0.1$ & $57.8 \mathrm{a}$
\end{tabular}

'Plants were subjected to $\mathrm{pH} 3.5$ or 4.0 for $10 \mathrm{~h}$ on each of three dates $(30,35$, and 40 days after transplanting). 'Mean separation in each column by Duncan's multiple range test at $P \leq 0.05$. 
Mineral analysis of leaf samples at harvest time indicated that all tissue nutrients at $\mathrm{pH} 3.5$ and 4.0 were within the normal range of concentrations for healthy growth of potatoes (data not shown); however, concentrations of certain nutrients were affected at $\mathrm{pH}$ 3.5. Tissue concentrations of $\mathrm{Mn}$ and $\mathrm{Fe}$ increased $40 \%$ and those of $\mathrm{N}$ and $\mathrm{P}$ decreased $10 \%$ with $\mathrm{pH}$ 3.5 compared to $\mathrm{pH} 4.0$ and 5.5. Enhanced $\mathrm{Mn}$ accumulation in the leaf tissues with $\mathrm{pH} 3.5$ may have resulted in the interveinal brown spots on leaves following the $\mathrm{pH}$ reductions. This presumed Mn toxicity symptom was consistent with a previous report on potatoes by Marsh and Peterson (1990). However, it is questionable if the changed nutrient concentrations in leaf tissues with $\mathrm{pH} 3.5$ affected particular physiological processes to promote tuberization; $\mathrm{pH}$ 4.0-treated plants exhibited no significant nutrient changes, yet were also induced to tuberize. In a previous study, withholding $\mathrm{N}$ induced tuberization (Krauss and Marschner, 1982), but tuberization was stimulated only after $\mathrm{N}$ had been withheld for several days. In our study, $\mathrm{N}$ was always provided to the plants, and the treatment period with reduced $\mathrm{pH}$ was only $10 \mathrm{~h}$.

Our results demonstrate that shot--term reductions of solution $\mathrm{pH}$ can significantly promote tuber initiation on potato plants grown with stolons immersed in liquid. Our data also suggest that for rapid and consistent tuber induction the intermittent $\mathrm{pH}$ levels need to be $<4.0$. Apparently with the low $\mathrm{pH}$ treatments, assimilate partitioning to shoots and roots was restricted and directed toward stolon development and tuber initiation. This solution-pH control procedure may be use to produce many small tubers for plant propagation.

\section{Literature Cited}

Cao, W. and T.W. Tibbitts. 1994. Responses of potatoes to solution $\mathrm{pH}$ levels with different forms of nitrogen.J.Plant Nutr. 17(1):109-126.

Hammer, P. A., T.W. Tibbitts, R.W. Langhans, an J.C. McFarlane. 1978, Baseline growth studies of 'Grand Rapids'lettuceincontrolled environments. J. Amer. Soc.Hort. Sci. 103:649-655.

Islam, A. K. M. S., D.G. Edwards, and C.J. Asher. 1980. pH optima for crop growth. Results of a flow solution culture experiment with six species. Plant \& Soil 54:339-357.

Jariel, D. M., S.U. Wallace, U.S. Jones, and HP. Samonte. 1991. Growth and nutrient composition of maize genotypes in acid nutrient solutions. Agron. J. 83:612-617.

Jones, J.B., B. Wolf, and H.A. Mills. 1991. Plant analysis handbook. Micro-Macro Publishing, Athens, Ga.

Krauss, A. and H. Marschner. 1982. Influence of nitrogen, day length and temperature on con- tents of gibberellic and abscisic acid and on tuberization in potatoplants.PotatoRes.25:1321.

MacLean,A.J.,J.J.Jasmin,andR.L. Halstead. 1967. Effectof lime on potato crops and on properties of a sphagnum peat soil.Can. J. Soil Sci. 47:8994.

Marsh, K.B. and L.A. Peterson. 1990. Gradients in Mnaccumulation and changes in plant form for potato plants affected byMntoxicity.Plant Soil 121:157-163

McLean,E.O.and J.R. Brown. 1984, Crop response to lime in the midwestern United States,p.267303.In:F. Adams (cd.). Soil acidity and liming. Amer. Soc. Agron., Madison, Wis.

Smith, O. 1938. Growth and development of the potato as influenced especially by soil reaction. Cornell Univ. Agr. Expt. Sta. Memoir 215, Ithaca, N.Y.

Tibbitts, T, W. and W. Cao. 1994. Solid matrix and liquidcultureproceduresforgrowth of potatoes. Adv. Space Res. (In press.)

Tibbitts,T.W.and R.M. Wheeler. 1987. Utilization of potatoes in bioregenerative life support systems. Adv. Space Res. 7:41154122.

Vreugdenhil, D. and P.C. Struik. 1989. An integrated view of the hormonal regulation of tuber formation in potato (Solarium tuberosum). Physiol. Plant. 75:525-531.

Wheeler,R.M., C.L. Mackowiak, J.C. Sager, W.M. Knott, and C.R. Hinkle. 1990. Potato growth and yield using nutrient film technique (NIT). Amer.Potato J. 67:177-187. 